\title{
Actividad Impedida de Recolectores de Mariscos y Pescadores Artesanales de la Isla de Maré, Baía de Todos los Santos
}

\author{
Atividade Impedida de Marisqueiros e Pescadores Artesanais da Ilha de Maré, Baía de Todos \\ os Santos
}

Ingrid Gil Sales Carvalho ${ }^{\text {ab }}$

\begin{abstract}
${ }^{a}$ Universidade de Salamanca-Espanha, Programa de Pós-Graduação Stricto Sensu em Estado e Governança Global. Espanha ${ }^{b}$ Universidade de Caratinga, Curso de Direito. MG, Brasil.

E-mail: ingridgsales@gmail.com.
\end{abstract}

\begin{abstract}
Resumén
Este artículo tiene como objetivo analizar cómo los pescadores artesanales y las recolectoras de mariscos de la Isla de Maré, en la Baía de Todos los Santos, en Brasil, han enfrentado la contaminación ambiental local. El ambiente de trabajo se entiende como el lugar donde las personas realizan sus actividades laborales. En el caso de los pescadores artesanales, el ambiente de trabajo se confunde con el ambiente natural en sí, y cualquier interferencia en este ambiente natural tiene un impacto directo e inmediato en la actividad laboral de estos trabajadores. Es una investigación bibliográfica y documental en la que se consultaron libros, documentos originales, artículos, trabajos de cursos, monografías, disertaciones, tesis, leyes, proyectos, reglamentos, informes y opiniones. También se llevó a cabo una investigación sobre el enfoque teórico en la clinica de la actividad y metodológico de enfoque etnográfico con el objetivo de comprender la percepción de las recolectores de mariscos y los pescadores de la Isla de Maré sobre la actividad impedida de ellos. Se verificó que en el caso específico de la Isla de Maré en la región de la Baía de Todos los Santos, esta se encuentra rodeada de compuestos químicos dañinos para el medio ambiente y para el ser humano. Esta contaminación del entorno natural y, por consiguiente, del entorno de trabajo de los pescadores y las recolectoras de mariscos, ha causado un retraso y, a veces, un impedimento para sus trabajos.
\end{abstract}

Palabras-clave: Derecho Ambiental del Trabajo. Derecho a la Salud. Pesca Artesanal. Medio Ambiente de Trabajo. Clinica de la actividad.

\section{Resumo}

Este artigo tem como objetivo analisar como as marisqueiras e os pescadores artesanais da Ilha da Maré, na Baía de Todos os Santos, no Brasil, enfrentaram a poluição ambiental local. O ambiente de trabalho é entendido como o local onde as pessoas realizam suas atividades de trabalho. No caso dos pescadores artesanais, o ambiente de trabalho é confundido com o próprio ambiente natural, e qualquer interferência nesse ambiente natural tem um impacto direto e imediato na atividade laboral desses trabalhadores. Trata-se de uma investigação bibliográfica e documental, na qual foram consultados livros, documentos originais, artigos, trabalhos de curso, monografias, dissertações, teses, leis, projetos, regulamentos, relatórios e instruções. Também foi realizada uma investigação sobre a abordagem teórica da Clínica da Atividade e metodológico de abordagem etnográfica, com o objetivo de compreender a percepção de pescadores artesanais e pescadores da Ilha de Maré sobre sua atividade. Verificou-se que, no caso especifico da Ilha de Maré, na região da Baía de Todos os Santos, ela é cercada por compostos químicos nocivos ao meio ambiente e ao ser humano. Essa contaminação do ambiente natural e, consequentemente, do ambiente de trabalho de pescadores artesanais e marisqueiras, causou adoecimento e, por vezes, um impedimento à realização do trabalho desses.

Palavras-chave: Direito Ambiental do Trabalho. Direito à Saúde. Pesca Artesanal. Ambiente de Trabalho. Clínica da Atividade.

\section{Introducción}

El objetivo de este artículo es abordar el concepto de la Clínica de Actividad enunciada por Yves Clot (1995, 2008, 2010a, 2010b) al referirse al impedimento directo e inmediato del trabajo de los pescadores artesanales y de las recolectoras de mariscos de la Isla de Maré, Baía de Todos los Santos, en Brasil. La Isla de Maré, aunque pertenece al Ayuntamiento de Salvador, la capital del estado de Bahía, está ubicada en la Baía de Aratu, al noreste de la Baía de Todos os Santos (BTS) y tiene importantes áreas industriales y militares en su entorno, como el Centro Industrial de Aratu (CIA), el Puerto de Aratu, la Base Naval de Aratu y el Comité de Promoción Industrial de Camaçari (COFIC) (CARVALHO, 2013; CARVALHO, et al., 2014).

La Isla de Maré tiene una extensión territorial de 13.79 $\mathrm{km}^{2}$, con una población de más de 6 mil habitantes que se declaran negros o marrones en más del $92.99 \%$ de sus habitantes (BRASIL, 2010; IBGE, 2010 apud CARVALHO et al, 2014), compuestos en su totalidad por comunidades llamadas: Itamoabo, Botelho, Santana, Neves, Praia Grande, Bananeiras, Maracanã, Porto dos Cavalos, Caquende y Martelo, Almendra, Ponta de Coroa, Ponta da 7 Cacimba, Ponta de Areia, Engenho de Maré y Ponta do Ermitão, cuya economía se basa en actividades como la pesca artesanal, la recolecta de mariscos, la plantación de insumos como bananas, cocos, caña de azúcar, artesanías, turismo y comercio local reducido (ESCUDERO, 2011; CARVALHO, 2013).

En una encuesta reciente realizada por la Fundación Cultural Palmares (FCP), ahora hay casi 5.000 comunidades de quilombolas o restos de quilombolas certificados en Brasil hoy, esto actualizado con la Ordenanza $n^{\circ}$ 96/2020 publicada en el Boletín Oficial (DOU) en 12/05/2020. Esa misma lista 
incluye a la Comunidad de Bananeirsa, la primera certificada en la Isla de Maré en 10/12/2004 por medio del Certificado $n^{\circ}$ 35/2004 y luego las comunidades de Martelo, Ponta Grossa y Porto dos Cavalos en 12/09/2005, a través del Certificado $n^{\circ}$ 37/2005 (BRASIL, 2020). En este sentido se puede decir que $60 \%$ del territorio de la Isla de Maré se refiere a comunidades quilombolas certificadas (RADIS, 2013).

La contaminación química que afectó no solo a la Isla, sino también a toda la BTS fue estudiada por el CRA (BAHIA, 2001, 2005 apud CARVALHO, 2013), que en la producción de sus informes verificó la gravedad de la contaminación química que se encuentra en la BTS, a través de la presencia de altos niveles de metales pesados e hidrocarburos del petróleo se encuentran en el agua, los sedimentos e incluso los alimentos marinos, alcanzando valores críticos para la salud humana, la flora y la fauna marinas.

El informe de la CRA (BAHIA, 2005 apud CARVALHO, 2013) concluyó que la contaminación química por metales pesados se produjo en BTS, con la mayor toxicidad observada en elementos químicos como el mercurio, el plomo y el cadmio en Madre de Deus, cerca de la Isla de Maré. La presencia de otros contaminantes químicos serios, como los hidrocarburos aromáticos policíclicos (HPA), se encontró presente en niveles que transgreden la legislación brasileña e internacional en el norte y este de la Baía de Todos os Santos, así como el Puerto de Aratú, Caboto y Pati, cerca de los pueblos de Bananeiras y Maracanã, en la Isla de Maré.

De acuerdo con el informe de la CRA (BAHIA, 2005 apud CARVALHO, 2013) antes mencionado, los animales marinos están contaminados por metales tóxicos como el mercurio, el plomo, el arsénico y el cadmio, son: los mariscos llamados popularmente como Sururu, Rala-coco, Lambreta, crustáceos conocidos como Siri, Cangrejo y Aratu y los pescados denominados Mullet, Arraia, Coró, Sardina, Platija y Carapeba.

Es importante tener en cuenta que no solo la CRA (BAHIA, 2001, 2005 apud CARVALHO, 2013) ha producido informes que atestiguan la contaminación ambiental en BTS, sino también investigadores del Instituto de Química (MACHADO; TAVARES, 1996; BANDEIRA; TAVARES, 1999; PLETSCH, 2007), investigadores del Instituto de Biología (AGUIAR, 2006) de la Universidad Federal de Bahía (UFBA) han defendido sus Conclusiónes del Curso, Disertaciones y Tesis, concluyendo que la Baía de Todos los Santos está contaminada por metales pesados que transgreden la legislación nacional e internacional.

Los metales pesados que se encuentran a gran escala en el BTS, como el aluminio, el arsénico, el plomo, el bario, el cromo, el mercurio, el cadmio y el estroncio, además de los hidrocarburos del petróleo y los surfactantes representan un riesgo para la salud humana, incluido el riesgo carcinogénico, a través del consumo diario de pescado. y mariscos por comunidades ubicadas en la región BTS, así como la contaminación y daños al medio ambiente natural (BAHIA, 2001, 2005 apud CARVALHO, 2013).

A pesar de los numerosos datos cuantitativos y cualitativos ya existentes y publicados en Revistas Científicas Nacionales e Internacionales, a través de artículos indexados (CARVALHO et al, 2014; REGO et al. 2018; HATJE et al., 2019; PENA, et al., 2019; SILVA, 2018) y las diversas encuestas realizadas por investigadores de la UFBA que demuestran plenamente que la falta de tratamiento de aguas residuales en Maré y de las áreas circundantes, las industrias ubicadas alrededor de Aratu y el Puerto de Aratu, son responsables por la guardia, manejo, producción, disposición y transporte de químicos y HPAs que causan contaminación ambiental local, en violación de la legislación nacional e internacional para metales pesados encontrados en mariscos y pescados recolectados en la área, como Cobre, Zinc, Cadmio, Aluminio, Bario, Cromo, Cadmio, Mercurio, Arsénico, Hierro, Manganeso, Selenio, Vanadio, Plomo y Estroncio, además de de hidrocarburos de petróleo y surfactantes (CRA 2001, CRA 2008, SOUZA, 2010, CARVALHO, 2013) no se habían adoptado medidas coercitivas efectivas por parte de las entidades públicas hasta ahora (COSTA; PENA, 2005; RIOS; RÊGO; PENA, 2011; PENA; FREITAS, 2011; PENA; MARTINS; REGO, 2013; CARVALHO, 2013; CARVALHO et al, 2014; PENA; ANGELIM; RÊGO, 2020).

Por tener conocimiente de que la región de la Isla de Maré, alrededor del BTS esté contaminada, y con eso contaminó el ambiente natural-laboral de pescadores artesanales y de las recolectoras de mariscos de Maré es necesario contextualizar la Clínica de la Actividad. Esta fue propuesta por primera vez en Francia, particularmente por el erudito Yves Clot (1995, 2008) a principio de la década de 1990. La Clínica de la Actividad es un enfoque teórico reciente en el campo de la psicología del trabajo, cuyas principales influencias son autores como Vygotsky, Bakhtin, Espinosa, Tosquelles, Le Guillant, entre muchos otros en los campos de la ergonomía y de la psicopatología del trabajo en Francia (CLOT, 1995, 2010a).

\section{Desarrollo}

\subsection{La Clínica de la Actividad}

Por lo tanto la Clínica de la Actividad busca redefinir el tema del trabajo, como alguien que crea en un contexto para la vida, que no se vuelve complaciente y subordinado a la realidad que se da o se impone. El trabajo, a su vez, se define como una actividad triple: para el sujeto (alcance de sus propios objetivos), para el objeto de la actividad (o la actividad real) y para el otro (la actividad del otro, con la que el sujeto tiene que lidiar para cumplir lo suyo. En la Clínica de Actividad, el trabajo es el principal operador tanto del desarrollo psicológico del sujeto como de su salud y bienestar (CLOT, 2008).

En este sentido, la Clínica de la Actividad propone un 
importante cambio conceptual al insistir en que las "causas" del sufrimiento en el trabajo no están en el tema, ni en la relación entre los sujetos, sino en el trabajo en sí. Clot (1995, 2008, 2010a) elabora el concepto de actividad impedida para referirse a un trabajo bloqueado, incapaz de permitir la libre confrontación del individuo y de los colectivos con los riesgos, los desafíos, las demandas reales de la actividad, es decir, con el objeto de este último.

La actividad se ve obstaculizada en la vida cotidiana por varias razones. Los aspectos destacados de desventajas se revelan cuando los individuos y los colectivos no pueden discutir los criterios de calidad del trabajo. El trabajo se impone simplemente para cumplirse. No hay discusión sobre cómo hacerlo, si hacerlo de una manera y no de otra, cómo mejorar la calidad del trabajo o el ejercicio en sí, y así sucesivamente. La actividad también se ve impedida cuando la organización del trabajo no ofrece los recursos para que los sujetos puedan lograrlo de acuerdo con sus aspiraciones, sus deseos (CLOT, 2008, 2010b).

Para la Clínica de la Actividad, especialmente para Yves Clot (2006), la actividad es lo que se hace para no hacer, lo que se debe hacer o aún lo que se hace sin desear hacer. Sin mencionar lo que hay que rehacer. Por lo tanto, se entiende que la actividad en sí es mucho más de lo que es perceptible en la actividad realizada. Del mismo modo, fatiga, traes agotamiento violento, estrés se entiende tanto por lo que los trabajadores no pueden hacer como por lo que hacen.

Según Clot (2006, 2008), el concepto de actividad debe incorporar lo posible y lo imposible para preservar las posibilidades del trabajador de comprender su desarrollo y/o su entrada en el "sufrimiento". Según el mismo autor (2001), dejar de lado tales conceptos, especialmente el de la actividad contradicha o impedida, en la análisi del trabajo, significa ignorar los conflictos vitales en que los trabajadores buscan escapar en lo real.

Está claro que el concepto de actividad impedida, según Clot (2006, 2008), es lo que no se puede hacer, lo que se busca hacer sin lograr, son los fracasos para tratar de llevar a cabo la actividad laboral. De esta manera, según Clot (2001, 2010a, 2010 b), toda actividad laboral consiste en lo prescrito (lo que se espera que haga el trabajador), en lo trabajo real (que es todas las posibilidades de la actividad del trabajador, lo que no se hace, lo que se hace), en lo que podemos hacer, lo que intentamos hacer sin lograr, lo que nos gustaría o podríamos hacer, lo que no hacemos, lo que pensamos o soñamos que podemos hacer en otro momento, etc. y en el trabajo realizado lo que realmente hizo el trabajador.

Por lo tanto, es precisamente entre el trabajo prescrito y el trabajo real que hay un espacio de ejercicio del trabajador que se llama actividad. Es subjetivo, un espacio de creatividad. Clot (2006) busca apoyo en Vygotsky y afirma que "el hombre está cada minuto lleno de posibilidades no cumplidas". Consistente con Clot (2006, 2008), la fatiga del trabajador se puede entender tanto por lo que hace como por lo que hace, y también no que se puede hacer. Para él, "lo que no puedes hacer y lo que te gustaría hacer, cuenta al menos tanto como lo que haces" en el curso de la actividad (CLOT, 2006).

Sin embargo, Clot (2001, p. 33) escribe sobre los efectos de la actividad impedida:

Entonces, la actividad internalizada, la fuente del sufrimiento, se invierte en el desarrollo subjetivo, entendida como la ampliación del radio de acción del sujeto dentro y fuera de él. Pero, como hemos visto, este desarrollo puede ser prohibido y la actividad dañada, congelada en procesos defensivos repetitivos. Se puede pensar con Ricoeur (1990) que el sufrimiento se define no solo por el dolor físico o mental, sino también por la disminución, o incluso la destrucción, de la capacidad de actuar, de hacer el poder, que se siente como agresión. a la integridad de sí mismo '. El sufrimiento es, para él, una impotencia para decir, hacer, expresar y estimar, es un impedimento. Allí donde la defensa es una protección pasiva que protege al sujeto del sufrimiento sin permitirle deshacerse de él, reduciendo su rango de acción al riesgo de anestesiarlo, la respuesta es una protección activa.

Lo que hace que uno sufra y se enferme, insiste Clot (2001), es la actividad impedida, el hecho de que el sujeto quiere trabajar y no poder. Es el sujeto de la acción que se enferma en el trabajo, un sujeto que se le impide "pasar por el acto", de actuar, de transformar el objeto de la actividad de acuerdo con sus ocupaciones previas, es decir, deseos, metas, motivos. En este sentido, Clot afirma ser menos sensible a la impotencia de los trabajadores que a su actividad impedida, a su deseo de trabajar a pesar de todos los obstáculos. Tal deseo, según Clot, puede reprimirse y envenenarse, pero nunca desaparece, porque si fuera posible, "el trabajo se convertiría en una actividad sin sujeto" (CLOT, 1995).

Aún en las consideraciones de Clot (2006), inactividad, inmovilidad frente al trabajo, es decir, la actividad deteriorada genera una tensión y puede ser más costosa que la actividad prescrita. En el caso de los pescadores artesanales y los recolectoras de mariscos de la Isla de Maré, existe una represión o impedimento de la actividad por la contaminación ambiental del lugar, que termina impidiendo la actividad laboral del mismo. Los testimonios recopilados de los residentes de la Isla de Maré en el distrito de Bananeiras, que son 03 pescadores artesanales y 02 recolectoras de mariscos, todos nacidos y criados en la comunidad de Bananeiras, que pescan y/o recolectan mariscos durante más de treinta años, se presentan como una forma de entender el significado de la contaminación ambiental en la Isla para ellos y como medio para percibir el sufrimiento, la angustia causada por el impedimento directo e inmediato de la actividad, debido a la contaminación ambiental local.

\subsection{Metodología}

En cuanto a la metodologia la investigación bibliográfica tuvo como objetivo localizar toda la bibliografía nacional que ya se hizo pública en relación con el objetivo general de este artículo, como libros, artículos científicos, trabajos de graduación, monografías, disertaciones de maestría y 
tesis doctorales. Así, estos dos métodos, la investigación documental y bibliográfica, permitieron el desarrollo de bases ideológicas y de principios para la continuación del presente estudio.

Por lo tanto, después de haber realizado la investigación bibliográfica y documental, se hizo uso de tres procedimientos de recolección de datos: entrevistas semiestructuradas o semi-estandarizadas, observación participante y enfoque etnográfico. Según Flick (2009, p. 203), los diversos tipos de entrevistas permiten el acceso solo a los informes de práctica, mientras que en los modos de observación, incluida la observación participante, proporciona acceso directo a las prácticas mismas. Al utilizar el método de observación participante, intentó obtener acceso al campo de investigación y a los pescadores artesanales y a las recolectoras de mariscos de la Isla de Maré. La observación sirvió, sobre todo, para proporcionar la investigadora orientaciones sobre el campo de estudio, cómo proceder, cómo dialogar con los pescadores y los recolectoras de mariscos de la Isla de Maré. Durante la observación durante un período de 06 meses, en el que se desarrolló el diario de campo, en el que se buscó documentar descriptivamente lo observado por la investigadora.

Seguro que la etnografía se refiere a la comprensión del pensamiento y el comportamiento humano manifestado en la rutina diaria de una determinada población, con el objetivo de percibir eventos menos predecibles o que se manifiestan particularmente en un contexto interactivo particular entre las personas. Para Geertz, practicar etnografía no es solo tratar de establecer relaciones, seleccionar informantes clave, transcribir textos, mapear campos o incluso llevar un diario de campo, para él "lo que define es el tipo de esfuerzo intelectual que representa: un riesgo complejo para una "descripción densa" (GEERTZ, 1989, p. 15).

Para Mattos (2001), la etnografía permite observar la forma en que grupos sociales específicos o ciertas personas llevan sus vidas, a fin de "revelar" el significado de la vida cotidiana, cómo actúan las personas. El propósito de este método es documentar, percibir, encontrar el significado de la acción. Lo que se verifica es que la práctica del método etnográfico exige tiempo, lo que implica largos períodos de observación (GEERTZ, 1989). Este tiempo se refiere a años, ya que para comprender el significado de ciertas acciones, prácticas o discursos, el investigador necesita un entendimiento, que solo puede obtener cuando se convierte en uno de los investigados. E investigar "convertirse en investigador" no se traduce en una tarea fácil, ya que requiere tiempo, habilidad y experiencia del investigador (FLICK, 2009, p. 214).

En el presente caso, elegimos utilizar un enfoque etnográfico y no utilizar el método etnográfico per se. Además, el enfoque etnográfico permitió una descripción más completa de la percepción de los pescadores artesanales y de mariscos en la Isla de Maré sobre su entorno de trabajo, si el entorno de trabajo es saludable, dónde se encuentra, si se ve afectado, por quién, por qué y qué hacer.

Como método de procedimiento se hizo uso de métodos históricos y monográficos, el primero porque percibe la actualidad como un reflejo de las influencias del pasado, de su consecuencia. Para Marconi y Lakatos (2010, p. 88), el método histórico consiste en investigar eventos pasados para verificar su influencia en la sociedad actual, porque según los autores: "Las instituciones han alcanzado su forma actual a través de cambios en sus componentes a lo largo del tiempo, influenciadas por el contexto cultural particular de cada época” (MARCONI; LAKATOS, 2010, p. 88).

El método monográfico, a su vez, consiste en el estudio de ciertos individuos, categorías específicas, con el objetivo principal de obtener generalizaciones. Según Marconi y Lakatos (2010, p. 88), la investigación debe estudiar el tema propuesto tratando de observar todas las circunstancias posibles que influyeron e influyen en el tema, examinándolos en todos sus aspectos.

\section{Resultados y Discusión}

Por supuesto este artículo presenta un enfoque diferenciado, que es la Clínica de la Actividad. Este enfoque teórico trae consigo conceptos de ergonomía y psicopatología del trabajo en un intento de percibir el continente oculto de la subjetividad en el trabajo (CLOT, 2001). Su formación se origina en Francia y encuentra refugio en su escritor principal, Yves Clot (2001, 2005, 2010a, 2010b). Son precisamente las relaciones entre actividad y subjetividad las que están en el centro del análisis de la Clínica de Actividad, que comprende el trabajo no solo como trabajo psíquico, sino como un campo abierto para el problema del sufrimiento.

Para Clot (2006) el sufrimiento es una actividad contradicha, un desarrollo impedido, a lo que él llama actividad impedida. Es una amputación del poder de actuar. Ricoeur entiende que el sufrimiento no solo se define por el dolor físico o mental, sino también "por la disminución, o incluso la destrucción de la capacidad de actuar, el poder de hacer, que se siente como un ataque a la integridad de uno mismo" (RICOUER, 1990, p.223).

Se comprende que la contaminación ambiental en la Isla de Maré termina al depreciar la práctica de la pesca artesanal y de las recolectoras de mariscos por parte de sus residentes, enfocándose en el concepto de actividad evitada, lo que no se puede hacer, y acercándose al pescador artesanal y la recolectora de mariscos de la Isla de Maré, un sufrimiento psíquico centrado en el impedimento del desarrollo de sus actividades laborales. En ese sentido, en las declaraciones mencionadas, los deponentes en las entrevistas semiestructuradas, cuyo tema era: ¿Como los pescadores artesanales y las recolectoras de mariscos darse cuenta de la contaminación ambiental en la Isla de Maré y cual percepción de las consecuencias de esta contaminación para ellos? Entienden que:

El Puerto de Aratu y Petrobrás están contaminando toda la Isla, matando mariscos y peces con derrames de petróleo y la contaminación que arrojan al mar. Además de lavar los barcos y dejar la tierra en el mar, todavía hay dragas que matan a muchos, incluso a peces ". (Testimonio de F.)

Fuimos allí para ver las dragas y en el momento de los derrames de petróleo en la Baía de Aratu. Aquí todo está contaminado, 
matamos muchos peces, incluso el pez llamado Baiacu, que es el pez más difícil de morir que hemos encontrado muertos. (Testimonio de M.)

Los testimonios de los residentes de la Isla demuestran la gravedad de la contaminación ambiental en el lugar que sienten. Que ven en la contaminación ambiental el motivo sui generis para la reducción de mariscos y peces en los manglares, ríos y mares. Asignando a la severidad de la contaminación ambiental en el lugar, la indicación de muertes de peces consideradas como más resistentes a la contaminación química por parte de la comunidad pesquera, como el pescado Baiacú.

Tengo 9 (nueve) hijos, mi madre tuvo 21 (veintiún) hijos y todos criaron a sus hijos con los pescados y mariscos de aquí en la Isla y ahora los peces y los mariscos se están agotando, por lo que la situación es muy difícil para los pescadores y mariscos En los viejos tiempos, iba a pescar con mis hijos, recolectábamos 15 (quince) kilos de mariscos al día y, con el dinero de la venta, compraba una casa, pagaba por el agua y la electricidad, compraba alimentos, hacía todo con dinero de los mariscos. (Testimonio de M.)

Hoy si puedes conseguir 1 (uno) o 2 (dos) kilos ya es mucho, incluso mucho, y esto, cuando la marea es muy buena. "Nací y crecí aquí, crié a mis hijos aquí y nunca quise irme aquí, a pesar de toda la contaminación que hicieron con la Isla. (Testimonio de E.).

Este es el significado de la contaminación ambiental que llega a la Isla de Maré para sus residentes y que, de hecho, ha impedido que los mariscos y los pescadores artesanales hagan de la pesca artesanal y la recolecta de mariscos sus principales actividades y, por lo tanto, una fuente de ingresos. Además, la pesca y los mariscos siempre se consideraron en la Isla de Maré como la principal fuente de ingresos para sus residentes (BAHIA, 2001 apud CARVALHO, 2014). Del testimonio recogido de $\mathrm{M}$. y E. es notable que la cantidad y la calidad del pescado y el pescado recolectados ya no son los mismos, de 15 kilos por día por años, 2 kilos por día en el presente, esto cuando la marea es buena para la pesca.

Todavía hay mariscos hoy, pero ni siquiera se compara con la cantidad de viejos. Hoy, vamos a los mariscos y encontramos los mariscos, ni siquiera tuvimos que buscarlos, los mariscos aparecieron, la una en el mismo lugar, las ostras ya nos mostraban gente. Fue muy hermoso de ver. Fue agradable de ver. (Testimonio de N.)

Aparte del hecho de que las almejas han diminuido de tamaño, no es como solía ser. La contaminación mató a los sururus, las ostras que apenas encuentras más. El pescado, especialmente el salmonete y la carapeba, sabe, cuando lo comes, puede ser frito, cocinado, asado, puedes probar el gusto de aceite, el gusto de aceite en sí, porque está todo contaminado. Abres el pescado y ves que sale aceite negro del propio pescado. (Testimonio de M.)

N. y M. continúan informando que el trabajo predominante y los medios de vida principales de la comunidad provienen de la venta de los mariscos y de la pesca y que dicha actividad se ha bloqueado, evitado, obstaculizado por la contaminación ambiental en el sitio, lo que ha llevado a una disminución de los mariscos, e incluso el cambio de tamaño, en su sabor, incluso encontrando en algunas especies de peces un tipo de “aceite negro", visible a simple vista. La preocupación de los habitantes de la Isla en la BTS reside en el futuro, que para ellos es una fuente de incertidumbre e inseguridad. ¿Cómo sobrevivir cuando tu única forma de trabajar y vivir está deteriorada?

Y dado que no hay más mariscos como antes y aquellos que tienen la gente ahí afuera ya saben que todo está contaminado, no podemos venderlo como antes. Por lo tanto, nuestros ingresos provienen incluso de programas gubernamentales como la familia o el subsidio de jubilación porque los mariscos ya no sirven como sustento para las familias de la Isla. No porque no queramos, nos gusta pescar y pescar. Son los productos que la naturaleza nos da, pero los "tiburones" los están matando. (Testimonio de N.)

Es culpa del gobierno, los inspectores del gobierno que no inspeccionan nada, y las industrias del Puerto de Aratu, Madre de Deus, Caboto y Petrobras también, que se ganaron la vida, tomaron nuestro trabajo y hoy dependemos para todo del gobierno. (Testimonio de F.)

La imposibilidad de practicar la pesca artesanal y la recolectadoras de mariscos en la Isla de Maré resultó en la dependencia directa de los pescadores, y la recolectadoras de mariscos y sus familias de los programas sociales del gobierno federal y/o las pensiones otorgadas por el Instituto Nacional de Seguridad Social (INSS), una buena parte de los cuales solo se debe a la edad, dificultades debido a la discapacidad, tiempo de contribución o especial (PENA, 2011).

Lo que sucede en la Clínica de la Actividad es que normalmente la persona responsable de la actividad que se le detene trabajar es la organización misma del trabajo al que está vinculada, que de alguna manera termina suprimiendo la actividad del trabajador, bloqueando eso. Sin embargo, en el caso de las recolectoras de mariscos y los pescadores artesanales en la Isla de Maré, deben considerarse como parte de las actividades que se llevan a cabo en forma autónoma, es decir, no están sujetos a una relación laboral y, por lo tanto, sus trabajadores no lo pueden recibir salarios, no tiene un permiso de trabajo firmado y no está dirigido por la Consolidación de las Leyes Laborales (CLT) en Brasil. Las recolectoras de mariscos y los pescadores artesanales no solo son responsables, sino también los creadores, ejecutores e inspectores de sus propisa organizaciónes de trabajo y condiciones de trabajo.

En este caso, la actividad obstaculizada de las recolectoras de mariscos y los pescadores artesanales en la Isla de Maré no se justifica por la organización del trabajo ni por las condiciones de trabajo, que dependen de estos trabajadores, sino por un factor externo, no relacionado con estos, que es el ambiente natural contaminado, que está contaminado en el ambiente de trabajo del mismo, un ambiente contaminado, dañado, que hace imposible pescar y/o recolectar mariscos con fines laborales.

Esto se debe a que, aunque no está escrito en el testimonio de los pescadores artesanales y las recolectoras de mariscos, es bien sabido que muchos de los hijos e hijas de estos no continuaron la actividad de los padres, que es una actividad 
milenaria que se transmite de generación en generación por tradición oral. Debido al impedimento de la actividad y, por lo tanto, esta nueva generación de hijos de pescadores artesanales y recolectoras de mariscos de la Isla de Maré ha trabajado en el comercio de Salvador o como sirvientas, jardineros y porteadores en condominios en Salvador, entre otras actividades (PEDRÃO, 2007, BANDEIRA; BRITO, 2011).

Lo que queda son los recuerdos. Los recuerdos de los tiempos en que los cangrejos ni las personas respetadas vinieron solo en una camada, en la época de caminar, en bandadas y, ustedes que salieron del frente, de tanto cangrejo que tenía y hoy, cuando lo ve, muerde la pelea y si No corre mucho, nunca ves el cangrejo, hoy huyen de nosotros [...] (Testimonio de A.).

Los tiempos pasados han recordado a las recolectoras de mariscos y pescadores artesanales la abundancia de animales marinos en la región, al tiempo que los comparan con un presente contaminado en el que la reducción en la cantidad y calidad de los mariscos, crustáceos y los peces se hicieron evidentes. Sin embargo, no verán los años futuros mejor que el presente para la naturaleza y para sí mismos, ya que comprenden que mientras las industrias permanezcan en la Baía de Aratu, más peces seguirán muriendo y más almejas disminuirán y desaparecerán.

Se observa, entonces, que la actividad de las recolectoras de mariscos y de los pescadores artesanales ha sido imposible hasta el punto de que las nuevas generaciones se vieron obligadas a buscar nuevas formas de sustento y, en consecuencia, trabajo. Además, los que aún pescan o tienen la actividad de las recolectoras de mariscos como las principales fuentes de ingresos o como las principales ocupaciónes. Porque ganan más de programas del gobierno federal, como Bolsa Família y el otorgamiento de pensiones por parte del INSS, que lo que actualmente ofrecen la venta de los mariscos y/o de la pesca. En este sentido, de la última generación de pescadores artesanales y pescadores de la Isla, pocos han logrado retirarse y otros aún trabajan con las plantaciones y el cuidado de otros animales para obtener el sustento propio y de su familia, de modo que tengan otras ocupaciones.

Para Clot (2006) el sufrimiento puede ser el resultado de una actividad contradictoria, un desarrollo prevenido. Es una amputación del poder de actuar. También se puede decir, más comúnmente, que es una actividad envenenada o intoxicada. Es evidente que se impidió la actividad de las recolectoras de mariscos y de los pescadores artesanales de la Isla de Maré y que esto trajo sufrimiento, angustia, un "drama" para aquellos trabajadores que tuvieron que adaptarse a estas circunstancias de la actividad evitada en casu.

\section{Conclusión}

En este caso, la actividad obstaculizada de las recolectoras de mariscos y los pescadores artesanales en la Isla de Maré trajo más que los efectos directos e inmediatos de la actividad obstaculizada misma, experimentada como una carga, sufrimiento, angustia de la imposibilidad de practicar una antigua actividad cultural. También provocó la incapacidad de estos trabajadores para sobrevivir mediante la pesca artesanal y la recolecta de los mariscos, que se vieron obligados a buscar otros medios de resistencia, para obtener formas de permanecer vivos.

Sin embargo, debe decirse que la actividad impedida puede tener otro destino, como el restablecimiento de los recursos de la acción de los trabajadores en la actividad en sí misma, donde el trabajo en sí es una vez más un momento para ampliar su rango de acción, la fuente de una actividad. En una fábrica, en un comercio, en cualquier actividad que tenga un empleador, la organización y las condiciones de trabajo son revisadas por los trabajadores y sus colectivos cuando toman el poder de actuar.

Sin embargo, en la Isla de Maré, los trabajadores, los pescadores artesanales y las recolectoras de mariscos son totalmente autónomos. La organización y las condiciones de trabajo no pueden ser modificadas, alteradas por un empleador e incluso por un organismo competente en el caso de trabajadores autónomos, trabajadores liberales que están registrados en sus órganos de clase. En la Isla de Maré, la pesca artesanal y los mariscos se traducen en un trabajo eminentemente informal, en el que los pescadores y las recolectoras de mariscos son solitarios en la defensa y promoción de un entorno de trabajo saludable, seguro, equilibrado y sostenible.

Se evidencia que la análisi de la actividad impedida, sin duda, dependerá de la categoría de trabajadores estudiados y de que el trabajador y sus colectivos determinarán cómo se llevará a cabo este estudio. En el caso de las recolectoras de mariscos y los pescadores artesanales en la Isla de Maré, la actividad impedida va más allá de lo que se está estudiando en fábricas, industrias, empresas, organizaciones e instituciones en las que la actividad impedida es un resultado sustancial de la organización del trabajo y sus condiciones.

En la Isla de Maré, la actividad para discapacitados de los pescadores artesanales y las recolectoras de mariscos se centra en la contaminación ambiental del lugar que les trajeron, además de la prohibición directa y propicia de las actividades históricas de carácter cultural, como las recolectoras de mariscos y la pesca artesanal, una forma de supervivencia de las comunidades pesqueras de la Isla, y un reajuste obligatorio y estructural en las formas y obras de los residentes de la Isla.

\section{Referencias}

AGUIAR, M.C.P. Micronúcleos em Macoma constricta (Bruguiere, 1792 (Bivalvia - Tellinidae): uma biomarca do estresse ambiental na Baía de Todos os Santos - BA. Salvador: Universidade Federal da Bahia, 2006.

BAHIA. Centro de Recursos Ambientais (CRA). Avaliação da qualidade das águas costeiras superficiais - Baía de Todos os Santos; Relatório Técnico, 2001.

BAHIA. Diagnóstico Ambiental da APA Baía de Todos os Santos. Volume II: Tomo II - Caracterização das Ilhas: Região NorteNordeste; Região Centro-Norte; Região Nordeste; Região Leste 
(Baía de Itapagipe). Salvador: julho, 2001.

BAHIA. Centro de Recursos Ambientais (CRA). SEMARH/ SEDUR/BID - CONSÓRCIO BTS HYDROS - Complementação do diagnóstico do grau de contaminação da Baía de Todos os Santos por metais pesados e hidrocarbonetos de petróleo: Relato Síntese; Salvador, 2005.

BANDEIRA, A.C.C.; TAVARES, T.M. Determinação de n-alcanos e hidrocarbonetos policíclicos aromáticos em fauna da Baía de Todos os Santos. Salvador: Universidade Federal da Bahia, 1999.

BANDEIRA, F.P.S.F.; BRITO, R.R. C. Comunidades pesqueiras na Baía de Todos os Santos: aspectos históricos e etnológicos. In: CAROSO, C.; TAVARES, F.; PEREIRA, C. (Org.). Baía de Todos os Santos: aspectos humanos. Salvador: EDUFBA, 2011. p.37-123.

BRASIL. Ministério do Desenvolvimento Agrário - MDA. Ilha da Maré (BA): Audiência discute regularização quilombola. Disponível em: <http:/goo.gl/LDUZoj>. Acesso em: 28 set. 2020.

BRASIL. Presidência da República. Programa Fome Zero. Comunidades tradicionais ocupam um quarto do território nacional. 2006. Disponível em: <http://www.fomezero.gov. $\mathrm{br} /$ noticias/comunidades-tradicionais-ocupam-um-quarto-doterritorio-nacional> Acesso em 14 jul. 2020.

CARVALHO, F. M. et al. Chumbo no sangue de crianças e passivo ambiental de uma fundição de chumbo no Brasil. Pan American J. Public Health, v. 13, n. 1, 2003.

CARVALHO, F. M. et al. Por um diálogo de saberes entre pescadores artesanais, marisqueiras e o direito ambiental do trabalho. Ciênc. Saúde Coletiva, v.19, n.10, p.4011-4022, 2014.

CLOT. Y. Le travail sans l'homme? Paris: La Découverte, 1995.

CLOT. Y. Clínica do trabalho, clínica do real. Le Journal dês Psyychologues, n. 185, 2001.

CLOT. Y. A função psicológica do trabalho. Petrópolis, Rio de Janeiro. Vozes, 2006.

CLOT. Y. Travail et pouvoir d'agir. Paris: PUF, 2008.

CLOT. Y. Le travail à coeur. Paris: La Découverte, 2010.

CLOT. Y. Entrevista: Yves Clot. Cad. Psicol. Soc. Trabalho, v.9, n.2, p. 99-107, 2006.

CLOT. Y. A Psicologia do trabalho na França e a perspectiva da clínica da atividade. Fractal: Rev Psicol., v. 22, n.1, p. 207-234, 2010a.

CLOT. Y. Trabalho e poder de agir. Belo Horizonte: FabreFactum, 2010b.

CLOT. Y. Clínica do trabalho e clínica da atividade. In: BENDASSOLLI, P.F.; SOBOLL, L.A.P. Clínicas do trabalho: novas perspectivas para compreensão do trabalho na atualidade. São Paulo: Atlas, 2011.

COSTA, D.F.; PENA, P.G.L. Persistem estratégias políticas ultraliberais para a saúde do trabalhador:uma contribuição ao debate. Ciênc. Saúde Coletiva, v.10, n.4, p.812-814, 2005.

ESCUDERO, S. Urbanização (In) sustentável em Ilha de Maré: estudo de caso da vila de Santana. Salvador: Universidade Católica do Salvador, 2011.

FLICK, U. Introdução à pesquisa qualitativa. Porto Alegre: Artmed, 2009.

GEERTZ, C. A interpretação das culturas. Rio de Janeiro: Guanabara, 1989.

HATJE, V. et al. Historical records of mercury deposition in dated sediment cores reveal the impacts of the legacy and presentday human activities in Todos os Santos Bay, Northeast Brazil. Marine Pollution Bull., v.145, p.396-406, 2019.

IBGE. Censo demográfico: censo 2010 por população - Bahia. Disponível Disponible en: http://www.ibge.gov.br/cidadesat/ topwindow.htm?1. Acceso en: 13 jan. 2019.

MACHADO, J. C. V.; TAVARES, T.M. Estudo do grau de contaminação por hidrocarbonetos nos sedimentos da Baía de Todos os Santos. Salvador: Universidade Federal da Bahia, 1996.

MARCONI, M. A.; LAKATOS, E.M. Fundamentos da metodologia científica. São Paulo: Atlas, 2010.

MATTOS, C.L.G. A abordagem etnográfica na investigação cientifica. Rio de Janeiro: UERJ, 2001.

PEDRÃO, F. Novos e velhos elementos da formação social do Recôncavo da Bahia de Todos os Santos. Rev. Centro de Artes, Hum. e Letras, v. 1, n. 1, 2007.

PENA, P.G.L. Programa de prevenção de riscos ocupacionais em pescadores e marisqueiras de comunidades pesqueiras da Baia de Todos os Santos. FORMULÁRIO-SÍNTESE DA PROPOSTA SIGProj EDITAL PROEXT 2011, 2011.

PENA, P.G.L. et al. Trabalho artesanal, cadências infernais e lesões por esforços repetitivos: estudo de caso em uma comunidade de mariscadeiras na Ilha de Maré, Bahia. Ciênc. Saúde Coletiva, v.16, n.8, p.3383-3392, 2011.

PENA, P.G.L. MARTINS, V.; REGO, R. F. Por uma política para a saúde do trabalhador não assalariado: o caso dos pescadores artesanais e das marisqueiras. Rev. Bras. Saúde Ocup., v.38, n.127, p.57-68, 2013. doi:. https://doi.org/10.1590/S030376572013000100009 .

PENA, P.G.L. et al. Derramamento de óleo bruto na costa brasileira em 2019: emergência em saúde pública em questão. Cad. Saúde Pública, v. 36, p. 1-5, 2020.

PLETSCH, A.L. Distribuição espacial de compostos orgânicos de estanho e metais em sedimentos costeiros e em Phallusia Nigra de áreas da Baía de Todos os Santos e Norte da Bahia. Salvador: Universidade Federal da Bahia, 2007.

RICOUER, P. Soi-memê comme un autre. Paris : Seuil, 1990.

RADIS. Águas contaminadas na Ilha de Maré. 2013. Disponível em: http:/www6.ensp.fiocruz.br/radis/sites/default/files/copia de_radis_129_23maio2013.p df Acesso em: 22 nov. 2019.

REGO, R. F. et al. Vigilância em saúde do trabalhador da pesca artesanal na Baía de Todos os Santos: da invisibilidade à proposição de políticas públicas para o Sistema Único de Saúde (SUS). Rev. Bras. Saúde Ocupv., v.43, supl. 1, e10s, 2018. doi: https://doi.org/10.1590/2317-6369000003618. 